\title{
openheart Pentoxifylline for vascular health: a brief review of the literature
}

\author{
Mark F McCarty, ${ }^{1}$ James H O'Keefe, ${ }^{2}$ James J DiNicolantonio ${ }^{2}$
}

To cite: McCarty MF,

O'Keefe $\mathrm{JH}$,

DiNicolantonio JJ.

Pentoxifylline for vascular health: a brief review of the literature. Open Heart 2016;3: e000365. doi:10.1136/ openhrt-2015-000365

Received 18 November 2015 Revised 7 January 2016 Accepted 11 January 2016

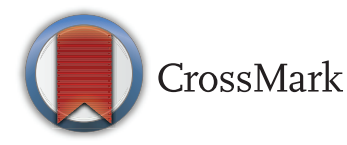

\footnotetext{
${ }^{1}$ Catalytic Longevity, Encinitas, California, USA ${ }^{2}$ Saint Luke's Mid-America Heart Institute, Kansas City, Missouri, USA
}

Correspondence to Dr Mark F McCarty; markfmccarty@gmail.com

\section{ABSTRACT}

Pentoxifylline is a methylxanthine derivative that has been used for several decades in the symptomatic management of intermittent claudication. For reasons that remain fairly obscure, this drug benefits blood rheology in a number of complementary ways: decreasing blood and plasma viscosity, lowering plasma fibrinogen while promoting fibrinolysis, and improving blood filterability by enhancing erythrocyte distensibility and lessening neutrophil activation. Antiinflammatory effects on neutrophils and macrophage/ monocytes-some of them attributable to pentoxifylline metabolites - appear to play a mediating role in this regard. Although clinical trials with pentoxifylline have often been too small in size to reach statistically significant findings regarding impacts on hard end points, a review of the existing literature suggests that pentoxifylline may have potential for slowing the progression of atherosclerosis, stabilising plaque, reducing risk for vascular events, improving the outcome of vascular events, dampening the systemic inflammatory response following cardiopulmonary bypass, providing symptomatic benefit in angina and intermittent claudication, enhancing cerebral blood flow in patients with cerebrovascular disease while slowing progression of vascular dementia, improving prognosis in congestive heart failure, and aiding diabetes control. This safe and usually well-tolerated drug works in ways quite distinct from other drugs more commonly used for cardiovascular protection, and hence may confer complementary benefit when used in conjunction with them. Major clinical trials of adequate statistical power are now needed to confirm the scope of benefits that pentoxifylline can confer; studies evaluating hard end points in acute coronary syndrome, stroke/transient ischaemic attack and systolic heart failure might be particularly valuable.

\section{PENTOXIFYLLINE IMPROVES THE RHEOLOGICAL PROPERTIES OF BLOOD IN MULTIPLE WAYS}

Pentoxifylline is a methylxanthine derivative used for the past three decades to treat intermittent claudication. ${ }^{1-3}$ In clinical dosestypically $400 \mathrm{mg}$ three times daily-it improves the rheological properties of blood in numerous ways: decreasing plasma and whole blood viscosity, in large measure owing to a reduction in plasma fibrinogen; increasing erythrocyte distensibility and suppressing erythrocyte aggregation; diminishing platelet aggregation; and increasing blood filterability by suppressing neutrophil activation. ${ }^{4-8}$ The activation of neutrophils renders them less distensible owing to an increase in the intracellular actin scaffold; hence, pentoxifylline improves the efficiency with which neutrophils can flow through the microvasculature. $^{9-15}$ Such an effect is particularly valuable when the pressure gradient across a microvasculature is diminished owing to an upstream stenotic obstruction; hence, it may be a key reason why pentoxifylline is clinically useful in intermittent claudication. The cumulative effect of a reduction in plasma viscosity, an increase in erythrocyte flexibility, and a suppression of neutrophil activation is improvement in capillary blood flow, particularly in vascular beds downstream from an arterial stenosis.

Pentoxifylline also exerts anti-inflammatory and antioxidant effects. The antioxidant effects appear primarily attributable to decreased neutrophil activation, as activated neutrophils generate superoxide via NADPH oxidase. ${ }^{16} \quad{ }^{17}$ There are also numerous reports that, in at least some clinical circumstances, pentoxifylline therapy lowers plasma levels of proinflammatory cytokines such as tumour necrosis factor (TNF) $\alpha$, interleukin (IL) 1 and IL-6. ${ }^{18-22}$ Since the latter cytokine evokes fibrinogen synthesis in hepatocytes, ${ }^{23}$ this may in part account for the decline in plasma fibrinogen levels also observed during pentoxifylline treatment.

\section{HOW DOES PENTOXIFYLLINE WORK AT THE MOLECULAR LEVEL?}

The molecular biology underlying these various effects remains rather murky. The standard explanation for pentoxifylline's utility is that it is a non-specific inhibitor of cAMP phosphodiesterases, and hence upregulates the effects of cAMP. ${ }^{24}$ But this effect of pentoxifylline is only observed in vitro 
when cells are exposed to near-millimolar concentrations of pentoxifylline, which are orders of magnitude higher than clinical plasma concentrations. ${ }^{25-27}$ Regrettably, the bulk of cell culture studies with pentoxifylline employ the concentrations required for phosphodiesterase inhibition-typically low millimolar levels. At these levels, pentoxifylline does indeed exert a number of intriguing effects, but many and perhaps most of these lack clinical pertinence. Plasma levels of pentoxifylline per se during clinical dosing are in the neighbourhood of $1 \mu \mathrm{M} .{ }^{17} 28{ }^{29}$ Curiously, several metabolites of this drug achieve plasma levels several-fold higher. ${ }^{30}$

A cell culture study examining the impact of pentoxifylline and its metabolites on neutrophil activation in vitro is particularly illuminating. ${ }^{17}$ This study is one of the few to examine the impact of clinically relevant concentrations of these agents. The researchers exposed neutrophils to agonists that provoke neutrophil activation (C5 Des Arg and formyl-methionylleucylphenylalanine) and measured the evoked increase in superoxide production. Whereas addition of pentoxifylline itself had no effect on superoxide production in concentrations ranging from 10 to $1000 \mathrm{ng} / \mathrm{mL}$, the three pentoxifylline metabolites tested (M1, M4 and M5) significantly inhibited evoked superoxide production within this concentration range. The impact of M5 (3'-carboxypropyl-3, 7-dimethylxanthine) may be most clinically pertinent, as its plasma concentrations are nearly an order of magnitude higher than those of pentoxifylline itself during clinical administration, and higher than that of any other metabolite (Cmax near $10 \mu \mathrm{M}$, or $2560 \mathrm{ng} / \mathrm{mL}$ ).

The ability of pentoxifylline therapy to lower plasma concentrations of inflammatory cytokines under certain circumstances seems likely to reflect an impact of this drug or its metabolites on monocyte/macrophage activity. One study enrolling eight healthy volunteers measured the response of their peripheral blood monocytes ex vivo to agents (titanium particles or lipopolysaccharide-LPS) that evoke TNF- $\alpha$ release; this assessment was repeated after the volunteers had ingested pentoxifylline ( $400 \mathrm{mg}$ five times daily) for 1 week. ${ }^{18}$ The pentoxifylline pretreatment was shown to significantly inhibit TNF- $\alpha$ release. Conceivably, pentoxifylline itself may be a mediator of this effect; in one study, the lowest concentration assessed, $10 \mu \mathrm{M}$, was found to suppress LPS-stimulated production of TNF- $\alpha$ and IL- 6 by alveolar macrophages from patients with sarcoidosis. ${ }^{31}$ A study evaluating a more clinically pertinent concentration$1 \mu \mathrm{M}$-would be warranted. The pentoxifylline metabolite M1, but not metabolites M4 and M5, appears to share this property. ${ }^{32}$

Pentoxifylline and its metabolite lisofylline (one of the isomers of its M1 metabolite) may act directly on erythrocytes to increase their distensibility and decrease their aggregability. In vitro, $10 \mu \mathrm{M}$ of these agents modestly increase erythrocytes deformability; the same concentration of pentoxifylline, but not lisofylline, inhibits erythrocyte aggregation. ${ }^{33}$
PENTOXIFYLLINE: MYRIAD POTENTIAL BENEFITS FOR VASCULAR HEALTH

Whereas intermittent claudication is clearly the bestdocumented indication for pentoxifylline, a thin but provocative set of studies suggests that this drug may have a broader role to play in the promotion of cardiovascular health.

\section{Prevention of atherosclerosis}

When rabbits were fed a cholesterol-enriched diet to induce atherosclerotic plaque, a clinically relevant daily oral dose of pentoxifylline $(40 \mathrm{mg} / \mathrm{kg}$ ) was found to decrease the area of aortic atherosclerotic plaque by $38 \% .^{16}$ The drug did not influence the rise in serum lipids, but plasma and aortic levels of malondialdehyde, a marker for oxidative stress, were $32 \%$ and $37 \%$ lower, respectively, in the pentoxifylline group. Since the neutrophil content of plaque tends to be low, it seems likely that anti-inflammatory effects on infiltrating monocytes and possibly on endothelial cells, mediated this benefit. Additionally, a 6-month controlled clinical trial enrolling adolescent type 1 diabetics has assessed the impact of pentoxifylline on common carotid intima-media thickness, an index of atheroma. ${ }^{34}$ This index declined in those receiving the drug, while it rose slightly in those receiving placebo $(\mathrm{p}<0.001)$.

\section{Prevention of cardiovascular events}

It appears that very few studies with pentoxifylline have examined its long-term impact on hard end points. However, a 6-month randomised placebo-controlled trial, enrolling patients with acute coronary syndromes (ACS), did make such an assessment. ${ }^{35}$ Patients received standard-dose pentoxifylline ( $400 \mathrm{mg}$ three times a day) or placebo along with other appropriate medications. The predetermined composite end point assessed consisted of death, non-fatal infarction and urgent rehospitalisation for ACS. At the end of the trial, 4 (13\%) of the patients in the pentoxifylline group and $11(34 \%)$ of the patients in the placebo group had achieved this end point $(p=0.04)$. The pentoxifylline-treated patients also experienced significant reductions in serum $\mathrm{C}$ reactive protein and TNF- $\alpha$ relative to the placebo group. While such a small trial evidently cannot yield any definitive conclusions, its encouraging results suggest that other larger trials examining pentoxifylline's impact on hard end points in at-risk patients should be conducted.

Although neutrophils are not prominent constituents of stable atherosclerotic plaque-and hence are not thought to play a direct role in the genesis of atheroma - they are found in unstable plaques of patients with ACS. ${ }^{36}$ Furthermore, among patients with angina, an increase in serum myeloperoxidase levels, indicative of neutrophil activation, is an adverse marker associated with increased risk for myocardial infarction in patients with angina. ${ }^{38} 39$ The emergence of neutrophillymphocyte ratio as an independent risk factor for coronary events in patients with diabetes or coronary 
lesions might reflect a role for activated neutrophils in the precipitation of such events ${ }^{40-42}$ - though this ratio may also be serving as a marker for inflammation. ${ }^{43}$

\section{Control of stable angina}

Clinical evidence regarding pentoxifylline's efficacy in this disorder is scarce, but mildly encouraging. An open trial enrolling only 11 patients reported significant $(\mathrm{p}<0.05)$ improvements in mean total exercise time (10.1 vs $7.7 \mathrm{~min}$ at baseline), time to onset of angina and heart rate at onset of angina after pentoxifylline therapy-albeit a strong placebo effect might have been involved. ${ }^{44}$ In a modest sized, underpowered doubleblind trial (21 participants), pentoxifylline therapy did not influence exercise time, but non-significant trends favouring pentoxifylline were seen in regard to angina attack rate (reduction of 1.5 attacks per week on drug vs 0.7 on placebo) and nitroglycerin use (reduction of 1.45 pills per week on drug vs 0.1 on placebo; $\mathrm{p}=0.10) .{ }^{45}$ Further clinical assessment in stable angina appears indicated.

\section{Prevention of stroke and transient ischaemic attacks}

Spontaneously hypertensive stroke-prone rats are a commonly used model of spontaneous stroke and cerebral ischaemia. Researchers evaluated the impact of daily oral pentoxifylline (100 or $200 \mathrm{mg} / \mathrm{kg}$ - the former dose appears clinically relevant after adjusting by the threefourth power of relative body mass) on development of brain ischaemia in these rats, as assessed by MRI. ${ }^{46}$ In the control group, all rats had developed brain abnormalities after 42 days. In the lower dose pentoxifylline group, $80 \%$ had done so after 70 days. In the higher dose group, no abnormalities were detected at 84 days. Pentoxifylline did not influence the elevated blood pressure in these rats, but histological examination of the brains of these rats showed that drug treatment prevented activation of microglia and influx of T-lymphocytes and macrophages. A 6-month randomised clinical trial enrolling patients experiencing transient ischaemic attacks (TIAs) assigned 73 patients to asprin +dipyridamole and 65 patients to pentoxifylline. ${ }^{47}$ During the trial, there were 80 TIAs in 19 patients in the aspirin/dipyridamole group, and 19 TIAs in 9 of those receiving pentoxifylline $(p<0.05)$. There were four nonfatal strokes in the former group, 2 in the latter. A subsequent larger study by the same group, likewise of 6-month duration, observed recurrent TIAs in $14 \%$ of patients receiving pentoxifylline, and $24.1 \%$ of those receiving aspirin/dipyridamole. ${ }^{48}$

\section{Treatment of acute ischaemic stroke}

Four controlled trials, enrolling a total of 763 patients, have assessed the impact of intravenous pentoxifylline on early mortality following acute ischaemic stroke. The daily doses employed ranged from 600 to $1200 \mathrm{mg}$, and were administered for 3-5 days immediately following stroke onset; in the three studies in which intravenous pentoxifylline was given for 3 days, this was followed up with oral pentoxifylline. A meta-analysis of these studies calculated a hazard rate of 0.65 (95\% CI 0.41 to 1.04$)$ for those receiving pentoxifylline. ${ }^{49}$ Hence, there was a strong trend (just barely missing statistical significance) suggesting that poststroke pentoxifylline could reduce early mortality by about one-third.

\section{Slowing of progression of vascular dementia}

At least four controlled clinical trials have evaluated the impact of pentoxifylline on progression of vascular dementia. A trend towards slowed progression was noted in all trials, and three found statistically significant benefit with respect to cognitive function. ${ }^{50-54}$ A likely mediator of this effect is increased perfusion of brain regions that are suboptimally perfused, owing to the drug's impact on blood viscosity and filterability. The ability of oral pentoxifylline in standard doses to enhance cerebral blood flow in patients with cerebrovascular disease has been demonstrated repeatedly. ${ }^{55-61}$

\section{Preservation of tissues after thrombolytic therapy}

Influx of activated neutrophils play a key role in the mediation of ischaemia-reperfusion tissue damage. ${ }^{62}$ Not surprisingly, pentoxifylline treatment has been reported to lessen such damage in numerous rodent studies, including studies focusing on the heart or brain. ${ }^{63-73}$

\section{Decreased inflammation and tissue damage following cardiopulmonary bypass}

A systemic inflammatory response syndrome (SIRS) is commonly observed following cardiopulmonary bypass (CPB), and can be associated with impaired organ function, as well as increased postoperative morbidity and mortality. ${ }^{74}$ Owing to its anti-inflammatory properties, preoperative or intraoperative administration of pentoxifylline has been evaluated in a number of small-sized or moderate-sized controlled studies as an adjuvant to CPB. ${ }^{75-86}$ Pentoxifylline has been administered orally in standard clinical doses for several days prior to surgery, or has been given intravenously at the time of surgery in various dose schedules $(\mathrm{eg}, 5 \mathrm{mg} / \mathrm{kg}$ as a bolus, followed by $1.5 \mathrm{mg} / \mathrm{kg} / \mathrm{h}$ continuous infusion until $3 \mathrm{~h}$ after cessation of CPB). Many of these studies concluded that pentoxifylline administration decreased SIRS after CPB, as assessed by serum levels of proinflammatory cytokines such as TNF- $\alpha$ and IL-6. ${ }^{79} 80{ }^{82-86}$ Decreased neutrophil activation (as assessed by serum polymorphonuclear leukocyte (PMN) elastase) and total leucocyte count was also reported in the pentoxifylline groups. ${ }^{79} 80$ Markers for endothelial activation (soluble adhesion factors), and liver, lung and renal function (serum creatinine) were found to be favourably influenced by pentoxifylline. ${ }^{75} 7778$ In a study which enrolled patients with left ventricular dysfunction, pentoxifylline improved left ventricular ejection fraction (LVEF) ${ }^{86}$ One study reported a reduction in haemolysis (serum haemoglobin) in the 
pentoxifylline group. ${ }^{81}$ Finally, two studies observed that patients receiving pentoxifylline benefited from a reduction in postoperative ventilation time and length of stay in the intensive care unit. ${ }^{79} 83$ Inclusion of pentoxifylline in the cardioplegia solution attenuated cardiac inflammation. ${ }^{66}$ Though these studies were not large or long enough to evaluate the impact of pentoxifylline on mortality risk following $\mathrm{CPB}$, they do suggest that, as an adjuvant to $\mathrm{CPB}$, this drug can rather notably dampen the postoperative inflammatory response that is thought to contribute to postoperative mortality.

\section{Improved outcomes in congestive heart failure}

The favourable effects of pentoxifylline on inflammation and blood rheology have prompted a number of relatively small controlled clinical trials examining pentoxifylline's long-term impact on outcomes in congestive heart failure $(\mathrm{CHF})$. Uniformly, these trials failed to observe a statistically significant effect of the drug on mortality during the follow-up periods. However, also uniformly, these studies also noted a trend towards lower mortality in the pentoxifylline group. These considerations prompted a recent meta-analysis of randomised controlled trials that had enrolled patients with $\mathrm{CHF}$ with LVEF $\leq 40 \%$, and assessed all-cause mortality. ${ }^{87}$ Six studies were included, comprising a total of 221 patients, most of 6 months duration. Remarkably, it was found that the patients receiving pentoxifylline had experienced a nearly fourfold reduction in mortality relative to the placebo-treated patients, with high statistical significance: $5.45 \%$ vs $18.3 \%$ (OR $0.29 ; 95 \%$ CI 0.12 to 0.74 ; $\mathrm{p}<0.01$ ).

\section{Improved diabetic control}

A very recent randomised controlled trial evaluated pentoxifylline $(400 \mathrm{mg}$ three times a day) in patients with type 2 diabetes over 6 months. ${ }^{88}$ A reduction in proteinuria $(23 \%)$ relative to that seen in the placebo group (4\%) was statistically significant $(\mathrm{p}=0.012)$. In addition, modest improvements in fasting blood glucose $(-10 \mathrm{mg} / \mathrm{dL})$, glycated haemoglobin $(-0.34)$ and homeostatic model assessment of insulin resistance (HOMA-IR) (-0.79) were seen in the pentoxifylline group that were significantly different relative to the small increases in these parameters observed in the placebo group. Since inflammation in adipose tissue can compromise systemic insulin sensitivity, the favourable impact of pentoxifylline on glycaemic control in this study may have reflected its anti-inflammatory actions.

\section{A CALL FOR CLINICAL RESEARCH}

At present, pentoxifylline is used primarily for relieving the symptoms of intermittent claudication. This brief overview suggests that it may have much broader potential for protecting vascular health and optimising tissue perfusion. Pentoxifylline combines a complementary array of effects that improve blood rheology-potentially beneficial in intermittent claudication, angina and vascular dementia-with anti-inflammatory effects that may oppose atherogenesis, ameliorate heart failure, aid diabetic control, lessen risk for plaque rupture and improve outcomes following vascular events or CPB. Because it works in ways that are entirely distinct from the drugs that are now in common use for cardiovascular protection-most notably statins, aspirin and angiotensin antagonists-it is likely to confer complementary benefit when used in conjunction with these wellestablished agents.

However, this exciting potential of pentoxifylline can only be realised if, at last, major multicentre trials are conducted to confirm or refute its utility for cardiovascular protection. Aside from its current accepted indication for intermittent claudication, other applications for pentoxifylline are currently supported by data that are too limited to permit definitive conclusions to be drawn. A trial in ACS would be particularly appropriate, as such patients are at high risk for vascular events, and a trial of moderate size and duration might be expected to observe significant benefit for hard end points, if the results of the pilot study in ACS are not a type I statistical error. Success with such a trial might then make it easier to get adequate funding support for larger trials evaluating pentoxifylline in coronary and cerebrovascular disease, heart failure, and diabetes.

Pentoxifylline lacks strong financial sponsorship, owing to the fact that its patent expired long ago. Our appreciation of the scope of pentoxifylline's utility for vascular protection may be constrained by the fact that the clinical trials assessing its various potential indications have been too small in size to reach definitive conclusions. It is instructive that, whereas every controlled trial of this drug in CHF failed to find a statistically significant impact on subsequent mortality, a meta-analysis of these trials found a large and highly significant protective effect in this regard. Larger studies are clearly indicated to evaluate pentoxifylline as an adjunct to current proven therapies.

Acknowledgements The authors thank Dr Charles Glassman for encouraging us to study the literature on pentoxifylline.

Contributors MFM conceived and wrote the first draft of this review. JHO and JJD contributed additional materials and made revisions.

Competing interests None declared.

Provenance and peer review Not commissioned; externally peer reviewed.

Data sharing statement No additional data are available.

Open Access This is an Open Access article distributed in accordance with the Creative Commons Attribution Non Commercial (CC BY-NC 4.0) license, which permits others to distribute, remix, adapt, build upon this work noncommercially, and license their derivative works on different terms, provided the original work is properly cited and the use is non-commercial. See: http:// creativecommons.org/licenses/by-nc/4.0/

\section{REFERENCES}

1. Hood SC, Moher D, Barber GG. Management of intermittent claudication with pentoxifylline: meta-analysis of randomized controlled trials. CMAJ 1996;155:1053-9. 
2. Girolami B, Bernardi E, Prins MH, et al. Treatment of intermittent claudication with physical training, smoking cessation, pentoxifylline, or nafronyl: a meta-analysis. Arch Intern Med 1999;159:337-45.

3. Salhiyyah K, Senanayake E, Abdel-Hadi M, et al. Pentoxifylline for intermittent claudication. Cochrane Database Syst Rev 2012;1: CD005262.

4. Ott $\mathrm{E}$, Lechner $\mathrm{H}$, Fazekas $\mathrm{F}$. Hemorheological effects of pentoxifylline on disturbed flow behavior of blood in patients with cerebrovascular insufficiency. Eur Neurol 1983;22(Suppl 1):105-7.

5. Strano A, Davi G, Avellone G, et al. Double-blind, crossover study of the clinical efficacy and the hemorheological effects of pentoxifylline in patients with occlusive arterial disease of the lower limbs. Angiology 1984;35:459-66.

6. Perego MA, Sergio G, Artale F, et al. Haemorrheological improvement by pentoxifylline in patients with peripheral arterial occlusive disease. Curr Med Res Opin 1986;10:135-8.

7. Soria J, Giovannangeli ML, Jolchine IE, et al. Pentoxifylline, fibrinogen and leukocytes. Blood Coagul Fibrinolysis 1990;1(45):485-7.

8. Fossat $\mathrm{C}$, Fabre $\mathrm{D}$, Alimi $\mathrm{Y}$, et al. Leukocyte activation study during occlusive arterial disease of the lower limb: effect of pentoxifylline infusion. J Cardiovasc Pharmacol 1995;25(Suppl 2):S96-100.

9. Armstrong M Jr, Needham D, Hatchell DL, et al. Effect of pentoxifylline on the flow of polymorphonuclear leukocytes through a model capillary. Angiology 1990;41:253-62.

10. Ciuffetti G, Mercuri M, Lombardini R, et al. Stable angina pectoris and controlled ischemia: what causes the abnormalities in whole blood filterability? Am Heart J 1990;119:54-8.

11. Ciuffetti G, Mercuri M, Ott C, et al. Use of pentoxifylline as an inhibitor of free radical generation in peripheral vascular disease. Results of a double-blind placebo-controlled study. Eur J Clin Pharmacol 1991;41:511-15.

12. Honess DJ, Kitamoto Y, Rampling MR, et al. Nicotinamide and pentoxifylline increase human leucocyte filterability: a possible mechanism for reduction of acute hypoxia. Br J Cancer Suppl 1996;27:S236-40.

13. Lavkan $\mathrm{AH}$, Astiz ME, Rackow EC. Effects of proinflammatory cytokines and bacterial toxins on neutrophil rheologic properties. Crit Care Med 1998:26:1677-82.

14. Drost EM, Selby C, Lannan S, et al. Changes in neutrophil deformability following in vitro smoke exposure: mechanism and protection. Am J Respir Cell Mol Biol 1992;6:287-95.

15. Frank RS. Time-dependent alterations in the deformability of human neutrophils in response to chemotactic activation. Blood 1990;76:2606-12.

16. Prasad K, Lee P. Suppression of hypercholesterolemic atherosclerosis by pentoxifylline and its mechanism. Atherosclerosis 2007:192:313-22.

17. Crouch SP, Fletcher J. Effect of ingested pentoxifylline on neutrophil superoxide anion production. Infect Immun 1992;60:4504-9.

18. Pollice PF, Rosier RN, Looney RJ, et al. Oral pentoxifylline inhibits release of tumor necrosis factor-alpha from human peripheral blood monocytes: a potential treatment for aseptic loosening of total joint components. J Bone Joint Surg Am 2001;83-A:1057-61.

19. Ferrari $P$, Mallon $D$, Trinder $D$, et al. Pentoxifylline improves haemoglobin and interleukin-6 levels in chronic kidney disease. Nephrology (Carlton) 2010;15:344-9.

20. González-Espinoza L, Rojas-Campos E, Medina-Pérez M, et al. Pentoxifylline decreases serum levels of tumor necrosis factor alpha, interleukin 6 and C-reactive protein in hemodialysis patients: results of a randomized double-blind, controlled clinical trial. Nephrol Dial Transplant 2012;27:2023-8.

21. Colson A, Willems B, Thissen JP. Inhibition of TNF-alpha production by pentoxifylline does not prevent endotoxin-induced decrease in serum IGF-I. J Endocrinol 2003;178:101-9.

22. Gutierrez-Reyes G, Lopez-Ortal P, Sixtos S, et al. Effect of pentoxifylline on levels of pro-inflammatory cytokines during chronic hepatitis C. Scand J Immunol 2006;63:461-7.

23. Fuller GM, Zhang Z. Transcriptional control mechanism of fibrinogen gene expression. Ann N Y Acad Sci 2001;936:469-79.

24. Windmeier C, Gressner AM. Pharmacological aspects of pentoxifylline with emphasis on its inhibitory actions on hepatic fibrogenesis. Gen Pharmacol 1997;29:181-96.

25. Beshay E, Croze F, Prud'homme GJ. The phosphodiesterase inhibitors pentoxifylline and rolipram suppress macrophage activation and nitric oxide production in vitro and in vivo. Clin Immunol 2001:98:272-9.

26. Verghese MW, McConnell RT, Strickland $A B$, et al. Differential regulation of human monocyte-derived TNF alpha and IL-1 beta by type IV cAMP-phosphodiesterase (cAMP-PDE) inhibitors. $J$ Pharmacol Exp Ther 1995;272:1313-20.
27. Semmler J, Gebert U, Eisenhut T, et al. Xanthine derivatives: comparison between suppression of tumour necrosis factor-alph production and inhibition of cAMP phosphodiesterase activity. Immunology 1993;78:520-5.

28. Yuen KH, Wong JW, Peh KK, et al. Comparative bioavailability study of two controlled-release pentoxifylline tablet preparations. Drug Dev Ind Pharm 2000;26:803-7.

29. Beermann B, Ings R, Mansby J, et al. Kinetics of intravenous and oral pentoxifylline in healthy subjects. Clin Pharmacol Ther 1985;37:25-8.

30. Nicklasson M, Björkman S, Roth B, et al. Stereoselective metabolism of pentoxifylline in vitro and in vivo in humans. Chirality 2002;14:643-52.

31. Tong Z, Dai H, Chen B, et al. Inhibition of cytokine release from alveolar macrophages in pulmonary sarcoidosis by pentoxifylline: comparison with dexamethasone. Chest 2003;124:1526-32.

32. Fantin M, Quintieri L, Kúsz E, et al. Pentoxifylline and its major oxidative metabolites exhibit different pharmacological properties. Eur J Pharmacol 2006;535:301-9.

33. Sloczynska K, Kozka M, Pekala E, et al. In vitro effect of pentoxifylline and lisofylline on deformability and aggregation of red blood cells from healthy subjects and patients with chronic venous disease. Acta Biochim Pol 2013;60:129-35.

34. Atabek ME, Kurtoglu S, Selver B, et al. Effectiveness of pentoxifylline on the cross-sectional area of intima media thickness and functions of the common carotid artery in adolescents with type 1 diabetes. J Pediatr Endocrinol Metab 2011;24:945-51.

35. Fernandes JL, de Oliveira RT, Mamoni RL, et al. Pentoxifylline reduces pro-inflammatory and increases anti-inflammatory activity in patients with coronary artery disease-a randomized placebo-controlled study. Atherosclerosis 2008;196:434-42.

36. Naruko T, Ueda M, Haze K, et al. Neutrophil infiltration of culprit lesions in acute coronary syndromes. Circulation 2002;106:2894-900.

37. Carbone F, Nencioni A, Mach F, et al. Pathophysiological role of neutrophils in acute myocardial infarction. Thromb Haemost 2013;110:501-14.

38. Baldus S, Heeschen C, Meinertz T, et al. Myeloperoxidase serum levels predict risk in patients with acute coronary syndromes. Circulation 2003;108:1440-5.

39. Brennan ML, Penn MS, Van Lente LF, et al. Prognostic value of myeloperoxidase in patients with chest pain. $N$ Engl J Med 2003;349:1595-604.

40. Papa A, Emdin M, Passino C, et al. Predictive value of elevated neutrophil-lymphocyte ratio on cardiac mortality in patients with stable coronary artery disease. Clin Chim Acta 2008;395:27-31.

41. Azab B, Chainani V, Shah N, et al. Neutrophil-lymphocyte ratio as a predictor of major adverse cardiac events among diabetic population: a 4-year follow-up study. Angiology 2013;64:456-65.

42. Arbel $Y$, Finkelstein $A$, Halkin $A$, et al. Neutrophil/lymphocyte ratio is related to the severity of coronary artery disease and clinical outcome in patients undergoing angiography. Atherosclerosis 2012;225:456-60.

43. Balta S, Celik T, Mikhailidis DP, et al. The relation between atherosclerosis and the neutrophil-lymphocyte ratio. Clin App/ Thromb Hemost. Published Online First: 9 Feb 2015. doi:10.1177/ 1076029615569568

44. Insel J, Halle AA, Mirvis DM. Efficacy of pentoxifylline in patients with stable angina pectoris. Angiology 1988;39:514-19.

45. Strauss WE, Parisi AF. Safety and efficacy of pentoxifylline in stable angina pectoris. Am J Cardiol 1993;71:342-4.

46. Banfi C, Sironi L, De Simoni SG, et al. Pentoxifylline prevents spontaneous brain ischemia in stroke-prone rats. $J$ Pharmacol Exp Ther 2004;310:890-5.

47. Herskovits E, Famulari A, Tamaroff $L$, et al. Preventive treatment of cerebral transient ischemia: comparative randomized trial of pentoxifylline versus conventional antiaggregants. Eur Neurol 1985:24:73-81.

48. Herskovits E, Famulari A, Tamaroff L, et al. Comparative study of pentoxifylline vs antiaggregants in patients with transient ischaemic attacks. Acta Neurol Scand Suppl 1989;127:31-5.

49. Bath PM, Bath-Hextall FJ. Pentoxifylline, propentofylline and pentifylline for acute ischaemic stroke. Cochrane Database Syst Rev 2004;(3):CD000162.

50. Sha MC, Callahan CM. The efficacy of pentoxifylline in the treatment of vascular dementia: a systematic review. Alzheimer Dis Assoc Disord 2003;17:46-54.

51. Blume J, Ruhlmann KU, de la Haye R, et al. Treatment of chronic cerebrovascular disease in elderly patients with pentoxifylline. $J$ Med 1992;23:417-32.

52. Black RS, Barclay LL, Nolan KA, et al. Pentoxifylline in cerebrovascular dementia. J Am Geriatr Soc 1992;40:237-44. 
53. No authors listed]. European pentoxifylline multi-infarct dementia study. Eur Neurol 1996;36:315-21.

54. Ghose K. Oxpentifylline in dementia: a controlled study. Arch Gerontol Geriatr 1987;6:19-26.

55. Passero S, Nardini M, Battistini N. Effect of pentoxifylline on cerebral blood flow in patients with chronic cerebrovascular disease. $J$ Int Med Res 1981;9:211-14.

56. Hartmann A. Effect of pentoxifylline on regional cerebral blood flow in patients with cerebrovascular disease. Pharmatherapeutica 1981;2:528-31.

57. Hartmann A. Effect of pentoxifylline on regional cerebral blood flow in patients with cerebral vascular disorders. Eur Neurol 1983;22 (Suppl 1):108-15.

58. Hartmann A. Comparative randomized study of cerebral blood flow after long-term administration of pentoxifylline and co-dergocrine mesylate in patients with chronic cerebrovascular disease. Curr Med Res Opin 1985;9:475-9.

59. Hartmann A, Tsuda Y. A controlled study on the effect of pentoxifylline and an ergot alkaloid derivative on regional cerebral blood flow in patients with chronic cerebrovascular disease. Angiology 1988;39:449-57.

60. Bowton DL, Stump DA, Prough DS, et al. Pentoxifylline increases cerebral blood flow in patients with cerebrovascular disease. Stroke 1989;20:1662-6

61. Torigoe R, Hayashi T, Anegawa S, et al. Effect of propentofylline and pentoxifylline on cerebral blood flow using 123I-IMP SPECT in patients with cerebral arteriosclerosis. Clin Ther 1994;16:65-73.

62. Schofield ZV, Woodruff TM, Halai R, et al. Neutrophils-a key component of ischemia-reperfusion injury. Shock 2013;40: 463-70.

63. Adams JG Jr, Dhar A, Shukla SD, et al. Effect of pentoxifylline on tissue injury and platelet-activating factor production during ischemia-reperfusion injury. J Vasc Surg 1995;21:742-8.

64. Carter MB, Wilson MA, Wead WB, et al. Pentoxifylline attenuates pulmonary macromolecular leakage after intestinal ischemia-reperfusion. Arch Surg 1995;130:1337-44.

65. Cerqueira NF, Hussni CA, Yoshida WB, et al. Effects of pentoxifylline and $n$-acetylcysteine on injuries caused by ischemia and reperfusion of splanchnic organs in rats. Int Angiol 2008;27:512-21.

66. Ustunsoy $\mathrm{H}$, Sivrikoz MC, Tarakcioglu M, et al. The effects of pentoxifylline on the myocardial inflammation and ischemia-reperfusion injury during cardiopulmonary bypass. $J$ Card Surg 2006;21:57-61.

67. Zhang M, Xu YJ, Saini HK, et al. Pentoxifylline attenuates cardiac dysfunction and reduces TNF-alpha level in ischemic-reperfused heart. Am J Physiol Heart Circ Physiol 2005;289:H832-9.

68. Gale SC, Hokama JY, Ritter LS, et al. Pentoxifylline reduces coronary leukocyte accumulation early in reperfusion after cold ischemia. Ann Thorac Surg 2001;71:1305-11.

69. Sirin $B H$, Yilik $L$, Coskun $E$, et al. Pentoxifylline reduces injury of the brain in transient ischaemia. Acta Cardiol 1998:53:89-95.

70. Toung TJ, Kirsch JR, Maruki Y, et al. Effects of pentoxifylline on cerebral blood flow, metabolism, and evoked response after total cerebral ischemia in dogs. Crit Care Med 1994;22:273-81.

71. Movassaghi S, Nadia SZ, Soleimani M, et al. Effect of pentoxifylline on ischemia-induced brain damage and spatial memory impairment in rat. Iran J Basic Med Sci 2012;15:1083-90.
72. Nadia SZ, Movassaghi S, Mohamadzadeh F, et al. Reduction in ischemic brain injury following the administration of pentoxifylline after transient global ischemia/ reperfusion in a rat model. Med $\mathrm{J}$ Islam Repub Iran 2015;29:193.

73. Vakili A, Zahedi khorasani M. Post-ischemic treatment of pentoxifylline reduces cortical not striatal infarct volume in transient model of focal cerebral ischemia in rat. Brain Res 2007;1144:186-91.

74. Jaffer U, Wade RG, Gourlay T. Cytokines in the systemic inflammatory response syndrome: a review. HSR Proc Intensive Care Cardiovasc Anesth 2010;2:161-75.

75. Barkhordari K, Karimi A, Shafiee A, et al. Effect of pentoxifylline on preventing acute kidney injury after cardiac surgery by measuring urinary neutrophil gelatinase-associated lipocalin. J Cardiothorac Surg 2011;6:8.

76. Butler J, Baigrie RJ, Parker D, et al. Systemic inflammatory responses to cardiopulmonary bypass: a pilot study of the effects of pentoxifylline. Respir Med 1993;87:285-8.

77. Boldt J, Brosch C, Piper SN, et al. Influence of prophylactic use of pentoxifylline on postoperative organ function in elderly cardiac surgery patients. Crit Care Med 2001;29:952-8.

78. Tsang GM, Allen S, Pagano D, et al. Pentoxifylline preloading reduces endothelial injury and permeability in cardiopulmonary bypass. ASAIO J 1996;42:M429-34.

79. Boldt J, Brosch C, Lehmann A, et al. Prophylactic use of pentoxifylline on inflammation in elderly cardiac surgery patients. Ann Thorac Surg 2001;71:1524-9.

80. Cağli K, Ulas MM, Ozișik K, et al. The intraoperative effect of pentoxifylline on the inflammatory process and leukocytes in cardiac surgery patients undergoing cardiopulmonary bypass. Perfusion 2005;20:45-51.

81. Golbasi I, Akbas H, Ozdem S, et al. The effect of pentoxifylline on haemolysis during cardiopulmonary bypass in open-heart surgery. Acta Cardiol 2006:61:7-11.

82. Iskesen I, Saribulbul O, Cerrahoglu M, et al. Pentoxifylline affects cytokine reaction in cardiopulmonary bypass. Heart Surg Forum 2006:9:E883-7.

83. Heinze $\mathrm{H}$, Rosemann $\mathrm{C}$, Weber $\mathrm{C}$, et al. A single prophylactic dose of pentoxifylline reduces high dependency unit time in cardiac surgery-a prospective randomized and controlled study. Eur $J$ Cardiothorac Surg 2007;32:83-9.

84. Otani S, Kuinose M, Murakami T, et al. Preoperative oral administration of pentoxifylline ameliorates respiratory index after cardiopulmonary bypass through decreased production of IL-6. Acta Med Okayama 2008;62:69-74.

85. Iskesen I, Kurdal AT, Kahraman N, et al. Preoperative oral pentoxifylline for management of cytokine reactions in cardiac surgery. Heart Surg Forum 2009;12:E100-4.

86. Mansourian S, Bina P, Fehri A, et al. Preoperative oral pentoxifylline in case of coronary artery bypass grafting with left ventricular dysfunction (ejection fraction equal to/less than $30 \%$ ). Anatol $J$ Cardiol 2015;15:1014-19.

87. Champion S, Lapidus N, Cherié G, et al. Pentoxifylline in heart failure: a meta-analysis of clinical trials. Cardiovasc Ther 2014;32:159-62.

88. Han SJ, Kim HJ, Kim DJ, et al. Effects of pentoxifylline on proteinuria and glucose control in patients with type 2 diabetes: a prospective randomized double-blind multicenter study. Diabetol Metab Syndr 2015;7:64. 